\title{
Е.Л. ВАСЯНИНА
}

\section{ФИНАНСОВЫЕ ОБЯЗАТЕЛЬСТВА: ПОНЯТИЕ И ЮРИДИЧЕСКАЯ ОТВЕТСТВЕННОСТЬ ЗА НАРУШЕНИЕ}

\begin{abstract}
В статье исследуется проблемы правотворческой реализации теоретической конструкции финансового обязательства. Особое внимание автор уделяет исследованию мер юридической ответственности, применяемых за нарушение финансовых обязательств, а также вопросам рецепции гражданско-правовых норм в финансовом законодательстве.

В иелях упорядочения системы мер имущественной ответственности за нарушение финансовых обязательств автор приходит к выводу о иелесообразности сокращчения числа штрафов за финансовые правонарушения и расширения перечня оснований применения в финансовом праве таких универсальных юридических конструкций, как возмещение вреда, взыскание неустойки, начисления проиентов.

Ключевые слова: финансовое обязательство, доходы, расходы, налог, рецеепия, ответственность, возмещчение ущзерба, взыскание неустойки.
\end{abstract}

Термин «финансовое обязательство» упоминается в законодательстве и судебной практике, однако в финансово-правовой науке развитию концепции финансовых обязательств до сих пор не уделяется должного внимания, что существенно тормозит развитие финансового законодательства.

Во многом это обусловлено сформированным в рамках гражданско-правовой доктрины узким подходом к определению природы обязательственных правоотношений, согласно которому «обязательство как научное понятие, имеет смысл и значение только тогда, когда оно рассматривается в качестве специфической правовой формы опосредования товарно-денежных отношений» ${ }^{1}$, а потому «никаких обязательств в публично-правовых отношениях не существует» ${ }^{2}$.

Однако обязательство, представляющее собой особую правовую связь между его субъектами, выступает в качестве способа воздействия на имущественные отношения ${ }^{3}$, охватываемые сферой регулирования, как частного, так и публичного права. Например, формирование и распределение государственных доходов «происходит посредством осуществления платежей по ряду обязательств, из которых некоторые рассматриваются в гражданском праве, некоторые же в других юридических дисциплинах» ${ }^{4}$, в частности, в трудовом, финансовом праве и т.д.

В правовой доктрине обязательство рассматривается как правовой режим, обеспечивающий взаимодействие между лицами, обладающими «противоположными качествами, и связанными между собой единством предмета, составляющего в одно и то же время предмет права, принадлежащего первому, и предмет долга, обременяющего последнего из этих лиц» 5 .

В отличие от гражданско-правовых, финансовые обязательства представляют собой правоотношения, имеющие особые основания возникновения, направленные на удовлетво-

\footnotetext{
${ }^{1}$ Гражданское право. Учебник. Часть І. Издание третье, переработанное и дополненное. / под ред. А. П. Сергеева, Ю. К. Толстого. - М.: ПРОСПЕКТ, 1998. С. 484.

${ }^{2}$ Фогельсон Ю. Б. Избраннее вопросы общей теории обязательств: Курс лекций.- Москва : Юрист, 2001. С. 62.

${ }^{3}$ Мамутов В. К. Хозяйственное право. Избранные труды. Екатеринбург: Бизнес, менеджмент и право, 2008. С. 101.

${ }^{4}$ Агарков М. М. Общая часть советского обязательственного права. дисс д-ра юрид. наук. М.1938. С. 21.

5 Первоначальный проектъ общихъ положеній объ обязательствахъ. Санкт-Петербург. Типографія Правительствующаго Сената. 1890. С. 2.
} 
рение публичных интересов, исполнение которых обеспечивается административноправовым методом и особым способом защиты прав субъектов ${ }^{6}$.

Формирования и исполнения финансовых обязательств направлено на обеспечение функционирования финансового механизма как инструмента воздействия на законы экономики, игнорирование которых может привести «к затруднениям в денежном обращении ...к нарушению пропорций в распределении национального дохода» ${ }^{7}$.

Вместе с тем осуществление финансовых обязательств в ряде случаев приводит к дестабилизации финансового механизма и, как следствие, - к разбалансировке экономики государства. Изложенное вызвано: во-первых, неэффективностью системы государственного управления, особенности функционирования которой приводят к усложнению структуры финансового обязательства; во-вторых, несовершенством правотворческой реализации теоретической конструкции финансового обязательства; втретьих, - отсутствием упорядоченной системы мер имущественной ответственности за нарушение финансовых обязательств.

1. Существенное влияние на формирование структуры финансового обязательства и порядок его исполнения оказывают особенности функционирования системы государственного управления. Особенно ярко эта взаимосвязь прослеживается на примере финансовых обязательств расходного типа, обеспечивающих реализацию механизма бюджетного финансирования.

Современная система государственного управления базируется на функционировании многочисленных сепаратных денежных фондов отдельных субъектов (государственных корпораций, саморегулируемых организаций и т.д.), наделенных властными полномочиями, что приводит к усложнению структуры финансового расходного обязательства, превращая его в трехстороннее правоотношение, одной из сторон которого выступает публичный субъект, выполняющий роль проводника бюджетных денег до их конечного получателя.

Как показывает анализ документов, составленных контрольно-счетными органами государства по результатам контрольных мероприятий, сложившийся порядок финансирования приводит к негативным экономическим последствиям для страны, поскольку расходы на финансовое обеспечение деятельности «посредников», участвующих в доведении бюджетных средств до их получателей, являются чрезмерно высокими. Например, Счетной палатой Российской Федерации выявлено неэффективное субсидирование моногородов через дочернюю структуру ВЭБ. РФ - Фонд развития моногородов ${ }^{8}$. А Контрольно-счетной палатой Санкт-Петербурга в ходе проведения контрольных мероприятий установлены факты необоснованного использования бюджетных субсидий «Фондом - региональный оператор капитального ремонта общего имущества в многоквартирных домах». Указанный фонд необоснованно расходовал средства субсидий, выделенных Жилищным комитетом на осуществление его уставной деятельности, что повлекло потери бюджета Санкт-Петербурга в общей сумме 221358,8 тыс. рублей 9 .

\footnotetext{
${ }^{6}$ Васянина Е. Л. Обязательства в финансовом праве : монография / Е. Л. Васянина.- Москва : РУСАЙНС, 2020. С. 13.

${ }^{7}$ Ровинский Е. А. Основные вопросы теории советского финансового права : монография / Е. А. Ровинский.2-е изд.. стер. -М.: Норма : ИНФРА-М, 2018. С. 20.

${ }^{8}$ Агапцов А. А., Шторгин С. И. Отчет о результатах экспертно-аналитического мероприятия «Мониторинг и оценка хода реализации приоритетной программы «Комплексное развитие моногородов». Утвержден коллегией Счетной палаты Российской Федерации 26 марта 2019 года // Бюллетень. 2019. № 7 (259). [Электронный pecypc] // URL: www.ach.gov.ru20.

${ }^{9}$ Информация о результатах контрольного мероприятия «Выборочная проверка законности, эффективности и целевого использования бюджетных средств, предоставленных в форме субсидий Жилищным комитетом некоммерческой организации «Фонд - региональный оператор капитального ремонта общего имущества в многоквартирных домах», контроль за реализацией региональных проектов в 2018-2019 годах и истекшем перио-
} 
Отсутствие эффективных инструментов государственного управления в современных условиях компенсируется возрастающей ролью бюджетного финансирования посредством формирования и исполнения финансовых обязательств в обход закона о бюджете. Например, исполнение федерального бюджета в 2020 году осуществлялось с учетом законодательно установленных особенностей, предусматривающих право Правительству Российской Федерации без внесения изменений в Федеральный закон «О федеральном бюджете на 2020 год и на плановый период 2022 и 2023 годов»: использовать средства Фонда национального благосостояния на покрытие дефицита в случае превышения базовой цены на нефть марки «Юралс» над среднефактической; увеличивать расходы и резервный фонд Правительства Российской Федерации с превышением общего объема расходов; перераспределять расходы и (или) направлять их в резервный фонд Правительства Российской Федерации по решениям Комиссии Федерального Собрания по перераспределению бюджетных ассигнований в текущем финансовом году и плановом периоде и т.д. ${ }^{10}$

Сложившийся подход в осуществлении бюджетного финансирования вызывает тревогу, поскольку ключевую роль в регулировании расходных финансовых обязательств играет закон о бюджете.

2. Анализ законодательства и правоприменительной практики позволяет сделать вывод о том, что правотворческая реализация теоретической конструкции финансового обязательства происходит посредством рецепции гражданско-правовых норм в финансовом законодательстве. С одной стороны, «рецепция нарушает нормальное развитие права» ${ }^{11}$ и может привести к искажению финансово-правовых институтов. С другой стороны, частноправовые конструкции компенсируют отсутствие специального регулирования в актах финансового законодательства, а заимствование гражданско-правовых норм обусловлено природой финансовых обязательств. Дело в том, что любая финансовая операция, совершаемая в сфере формирования и распределения публичных доходов, по своей сущности является гражданско-правовой сделкой, совершенной в финансово-правовой форме, а применяемая частноправовая конструкция является лишь способом правового регулирования финансовых отношений, охватываемых сферой действия публичного права.

Однако существует опасность того, что активное заимствование гражданскоправовых инструментов может привести к нарушению принципов реализации финансового механизма, к раздвоению между финансово-правовой сферой и искусственным аппаратом юридической техники.

Следует учитывать, что «рецепция гражданско-правовых норм выступает лишь технико-юридическим приемом» 12 , не изменяющим природу и сферу регулирования финансовых обязательств. С этой точки зрения недопустимой представляется сложившаяся практика, в рамках которой рассмотрение споров, возникающих по поводу исполнения соглашений о предоставлении бюджетных субсидий, целиком отдается на откуп гражданскому праву $^{13}$. В таком случае оценка обоснованности использования бюджетных средств осуществляется без учета принципов функционирования бюджетной системы государства.

де 2020 года» [Электронный ресурс] // URL: https://ksp.org.ru/article/633200020/1670/Informaciya-o-rezultatahkontrolnogo-meropriyatiyaVyborochnaya-proverka-zakonnosti-effektivnosti-i-celevogo-ispolzovaniya-byudzhetnyhsredstv-predostavlennyh-v-forme-subsidiy-Zhilischnym-komitetom-nekommercheskoy-organizacii-Fond--regionalnyy-operat

10 Оперативный доклад Счетной палаты Российской Федерации Об исполнении федерального бюджета и бюджетов государственных внебюджетных фондов (январь - декабрь 2020 года) [Электронный ресурс] // URL: https://ach.gov.ru/audit/oper-2020

${ }^{11}$ Моддерман В. Рецепция римского права. С- Петербругъ. Типо-Литографія А. Е. Ландау. Площадь Большого Театра, 2. 1888. С. 86.

${ }^{12}$ Волкова Н. Н. Рецепция гражданско-правовых норм в налоговом законодательстве : автореф. дис. ..... канд. юрид. наук. - М., 2008. - 24 с.

${ }^{13}$ Определение Судебной коллегии по экономическим спорам Верховного Суда РФ от 19 января 2018 № 308 ЭС17-9296 по делу N А32-41306/2016; Определение Верховного Суда РФ от 28 февраля 2018 № 304-ЭС1723700 по делу № А27-4106/2017 // СПС «КонсультантПлюс». 
Другим примером, позволяющим проиллюстрировать негативные последствия, вызванные бесконтрольным заимствованием гражданско-правовых конструкций, является сложившийся порядок расторжения государственных контрактов. Отсутствие в финансовом законодательстве положений, конкретизирующих основания и условия расторжения государственных контрактов по соглашению сторон может приводить к необоснованному использованию бюджетных средств. В частности, эксперты отмечают, что контракты на потребление ресурсов, источниками которых являются естественные монополии (электрическая и тепловая энергия, водоснабжение и водоотведение и т. д.), расторгаются в связи с умыслом заказчиков изначально заложить большую сумму, чтобы затем при расторжении контракта высвободить эти денежные средства для иных закупок, которые не планировались и не были заложены в плане-графике ${ }^{14}$.

Учитывая изложенное, базирующаяся на рецепции гражданско-правовых норм, правотворческая реализация теоретической конструкции финансового обязательства в каждом конкретном случае должна сопровождаться конкретизацией пределов заимствования частноправовых инструментов регулирования.

3. Отсутствие упорядоченной системы мер имущественной ответственности за нарушение финансового законодательства привело к формированию достаточно сложного механизма взыскания штрафных санкций с субъектов финансовых обязательств. Например, за нарушение налоговых обязательств одновременно могут быть применены штрафные санкции, установленные НК РФ, КоАП РФ, УК РФ, меры имущественной ответственности, предусмотренные гражданским законодательством, а также дополнительные имущественные обременения, закрепленные законодательством о налогах и сборах, к которым, в частности, относятся пени, взыскание налога в двойном размере ${ }^{15}$ и т.д. Внушительный объем источников, закрепляющих санкции за нарушение налоговых обязательств, в ряде случаев приводит к необоснованному расширению круга субъектов ответственности, в роли которых могут оказаться лица, не имеющие непосредственное отношение к экономическому основанию налога.

Во многом это обусловлено современной трактовкой природы обязательства. В отличие от концепции обязательств, разработанной в римском праве, в рамках которой «обязательство понималось исключительно как личная связь, и изменить кредитора и должника означало уничтожить само обязательство» ${ }^{16}$, в современной правовой доктрине обязательство оторвано от личности должника и кредитора.

Такой подход к пониманию природы обязательственного правоотношения вызывает ряд вопросов, касающихся оснований перемены лиц в финансовом обязательстве и, как следствие, - определения круга субъектов ответственности за нарушение финансовых обязательств. Особенно остро указанная проблема проявляется в налогово-правовой сфере. Например, с учетом подходов, выработанных в практике высших судебных инстанций, обязанными субъектами в рамках финансового (налогового) обязательства помимо должника, который изначально является стороной правоотношения, при определенных условиях могут выступать и такие лица, как: наследники контролирующего должника лица, иные субъекты, имеющие отношение к имуществу этого лица; лица, используемые в качестве инструмента для сокрытия принадлежащего контролирующему лицу имущества; должност-

\footnotetext{
14 Высокая доля расторжения контрактов в рамках закона о контрактной системе: Аналитический доклад (подготовлен аналитическим центром при Правительстве Российской Федерации) [Электронный ресурс] // URL:

Publications/analitika/2021/для_публикации_на_сайте_АЦ_(Расторжение_контрактов).pdf https://ac.gov.ru/uploads/2-

${ }_{15}$ Например, согласно п. 16 ст. 396 Налогового кодекса Российской Федерации в отношении земельных участков, приобретенных в собственность физическими лицами для индивидуального жилищного строительства, исчисление суммы налога производится с учетом коэффициента 2 по истечении 10 лет с даты государственной регистрации прав на данные земельные участки вплоть до государственной регистрации прав на построенный объект недвижимости.

${ }^{16}$ Годэмэ Е. Общая теория обязательств / Е. Годэмэ - М.: Книга по Требованию,2020. С. 459.
} 
ные лица организации-налогоплательщика ${ }^{17}$. Например, в одном из решений ВС РФ отметил, что долг, возникший из субсидиарной ответственности при банкротстве, может передаваться по наследству, поскольку он подчиняется такому же режиму, что и задолженность из других деликтных обязательств, и не имеет неразрывной связи с личностью ${ }^{18}$. В другом решении ВС РФ пришел к выводу о том, что вред кредиторам может быть причинен не только доведением должника до банкротства, но и умышленными действиями, направленными на создание невозможности получения кредиторами полного исполнения за счет имущества контролирующих должника лиц, виновных в банкротстве должника ${ }^{19}$.

Расширение круга субъектов ответственности приводит к нарушению принципа формальной определенности финансово-правовой нормы, что в условиях непредсказуемой судебной практики, существенно ослабляет гарантии защиты прав субъектов финансового правоотношения.

Другая серьезная проблема в сфере применения мер ответственности за нарушение финансовых обязательств заключается в том, что в современных условиях отсутствие эффективных финансово-правовых инструментов воздействия на экономику компенсируется увеличением числа санкций за нарушение финансовых обязательств. Особенно ярко это можно проиллюстрировать на примере составов административных правонарушений в сфере государственных (муниципальных) закупок. Закрепленные в КоАП РФ штрафы за нарушение законодательства о госзакупках не позволяют обеспечить эффективность исполнения государственных контрактов, являющихся одной из форм реализации бюджетного финансирования. По мнению Счетной палаты Российской Федерации, «система госзакупок по-прежнему характеризуется преобладанием неконкурентных способов закупок и для ее дальнейшего развития не хватает качественных критериев оценки эффективности закупок» ${ }^{20}$.

Помимо изложенного финансово-правового регулирование начинает выстраиваться в обход законодательства об административных правонарушениях путем исключения из механизма финансирования закупочных процедур. Например, масштабное бюджетное субсидирование позволяет выводить объем бюджетных средств из сферы санкционирования расходов федерального бюджета, из области регулирования Федерального закона от 05 апреля 2013 № 44-Ф3 «О контрактной системе в сфере закупок товаров, работ, услуг для обеспечения государственных и муниципальных нужд» ${ }^{21}$. Кроме того, в отдельных случаях законодатель как будто бы сознательно устраняет конкурентные процедуры. Например, согласно Федеральному закону от 31 декабря 2017 № 505 «О внесении изменений и дополнений в отдельные законодательные акты Российской Федерации» госкомпании, госкорпорации, естественные монополии вправе проводить закупки у взаимозависимых лиц, минуя конкурентные процедуры.

Ярким примером, позволяющим продемонстрировать нецелесообразность увеличения количества составов административных правонарушений в финансовой сфере, является ситуация с введенными санкциями на необоснованное размещение государственными корпорациями бюджетных средств в банках. Несмотря на закрепление в КоАП РФ соответствующего состава правонарушения, Счетная палата Российской Федерации из года в год продолжает выявлять указанные нарушения. По результатам контрольных и экспертноаналитических мероприятий контрольный орган приходит к выводу о том, что значительные объемы средств, предоставленные государственным корпорациям, используются не в полном объеме и размещаются на депозитах и счетах в кредитных организациях, по кото-

\footnotetext{
${ }^{17}$ Постановление Конституционного Суда РФ от 08 декабря 2017 № 39-П //СЗ РФ. 2017.№ 51.Ст. 7914.

${ }^{18}$ Определение ВС РФ от 16 декабря 2019 г. № 303-ЭС19-15056 // СПС «КонсультантПлюс».

${ }^{19}$ Определение ВС РФ от 23 декабря 2019 г. № 305-ЭС19-13326 // СПС «КонсультантПлюс».

20 Отчет о результатах экспертно- аналитического мероприятия «Мониторинг развития системы государственных и корпоративных закупок в Российской Федерации за 2019 год». [Электронный pecypc] // URL : https://ach.gov.ru/upload/iblock/fea/fea86920fc7f4c8b39262ce74beb32d8.pdf

21 Запольский С. В., Васянина Е. Л.Субсидии и гранты - правовые инструменты развития экономики» // Хозяйство и право №11 2020.С.88-100.
} 
рым государственные корпорации получают проценты по неснижаемому остатку средств на счете. В частности, общий объем временно свободных средств государственных корпораций по состоянию на 1 апреля 2021 года составил порядка 225 млрд рублей ${ }^{22}$.

Сложившийся подход к финансовому обеспечению деятельности государственных корпораций нарушает такой основополагающий принцип бюджетного финансирования, как принцип единства кассы.

Приведенные примеры позволяют проиллюстрировать, что увеличение числа штрафов при отсутствии фундаментальных правовых условий осуществления экономической деятельности участниками гражданского оборота приводит к тому, что штрафная санкция из карательной меры превращается в способ правового регулирования финансовых отношений, а фискальная функция штрафа начинает преобладать над карательной и регулятивной функциями наказания.

Очевидно, что в современных условиях требуется упорядочение системы мер имущественной ответственности за нарушение финансовых обязательств. Это можно достичь, во-первых, посредством сокращения числа шрафных санкций за нарушения финансового законодательства, а во-вторых, - в результате преодоления разрыва между процедурами привлечения к ответственности, предусмотренными частным и публичным правом.

Подобная схема совершенствования системы мер юридической ответственности была закреплена в постановлении Совмина СССР от 30 июля 1988 г. № 929, согласно которому в качестве основных направлений упорядочения системы мер ответственности, помимо сокращения числа штрафов, были обозначены взыскание неустойки и возмещение убытков ${ }^{23}$.

В современных условиях законодатель и правоприменитель активизируют рецепирование гражданско-правовых мер ответственности в фискальное, бюджетное законодательство, законодательство о государственных расходах. Например, эффективная модель реализации мер принуждения за нарушения бюджетного законодательства, основанная на применении конструкции возмещения ущерба, закреплена в ст. $270^{2}$ БК Р $\Phi^{24}$. В соответствии с указанной статьей нарушение субъектом расходных финансовых обязательств в части направлений использования бюджетных средств является основанием для предъявления контролирующим органом требования о возмещении ущерба, причиненного бюджетной системе Российской Федерации.

Постановлением Правительства РФ от 25 августа 2017 № 1008 «О порядке осуществления мониторинга и контроля реализации самоокупаемых инфраструктурных проектов, реализуемых юридическими лицами, в финансовые активы которых размещаются средства Фонда национального благосостояния и (или) пенсионных накоплений, находящихся в доверительном управлении государственной управляющей компании, на возвратной основе, целевого использования средств Фонда национального благосостояния при финансировании указанных проектов и внесении изменений в некоторые акты Правительства Российской Федерации» введен механизм обратного выкупа эмитентом ценных бумаг, приобретенных Министерством финансов РФ за счет средств Фонда национального благосостояния, в целях финансирования инфраструктурных проектов ${ }^{25}$. Фактически реализация данного механизма направлена на возмещение ущерба, причиненного бюджетной системе в случае, когда бюджетные средства, предоставленные для целей финансирования публич-

\footnotetext{
22 Оперативный доклад Счетной палаты Российской Федерации «Об исполнении федерального бюджета и бюджетов государственных внебюджетных фондов» (январь - март 2021 года) [Электронный pecypc] // URL: https://ach.gov.ru/upload/iblock/eae/e6sisxlo1pmgkwbc5x18958gknip3cp1.pdf

${ }^{23}$ Постановление Совмина СССР от 30 июля 1988 г. № 929 «Об упорядочении системы экономических (имущественных) санкций, применяемых к предприятиям, объединениям и организациям» // Свод законов СССР. - Т. 5. - С. 6-66-1 (извлечение).

24 Васянина Е. Л. Обязательства в финансовом праве : монография / Е. Л. Васянина.- Москва : РУСАЙНС, 2020. C. 119.

${ }^{25}$ Васянина Е. Л. О правовой природе бюджетного финансирования // Финансовое право. 2021. № 5. С. 3-6.
} 
ных расходов, используются в качестве инструмента обогащения субъектов финансового обязательства.

Возможности применения гражданско-правовых норм при взыскании фискальной задолженности и штрафных санкций расширяются посредством использования в хозяйственных договорах, заключенных между участниками гражданского оборота, конструкции заверения об обстоятельствах, установленной ст. $432^{2}$ ГК РФ. Например, требование о возмещении убытков в размере суммы, признанной налоговым органом необоснованной налоговой выгодой, было предъявлено и удовлетворено судом ${ }^{26}$ на основании недостоверности заверений лица об обстоятельствах, имеющих значение для заключения и исполнения гражданско-правового договора. Более того, положения налогового законодательства, нацеленные на восстановление нарушенного экономического положения субъекта финансового обязательства, суды рассматривают через призму гражданско-правовых норм. Так, суд указал, что тот факт, что налоговые вычеты предусмотрены нормами налогового, а не гражданского законодательства, не препятствует их признанию в качестве особого механизма компенсации расходов хозяйствующего субъекта ${ }^{27}$.

Приведенные примеры позволяют проиллюстрировать подход, согласно которому имеющие универсальный характер конструкции «возмещение ущерба» и «взыскание неустойки» могут конкурировать с процедурами взыскания штрафных санкций за правонарушения, влекущие негативные финансовые последствия для бюджетной системы государства.

Принимая во внимание изложенное, а также учитывая риск-ориентированный подход, лежащий в основе совершенствования института административной ответственности 28 , следует провести работу по сокращению числа штрафов, взимаемых за нарушение финансового законодательства.

В целях правотворческой реализации теоретической конструкции финансового обязательства целесообразно продолжить рецепирование гражданско-правового регулирования в финансовом законодательстве, в том числе в части применения ответственности за финансовые правонарушения.

Для того, чтобы исключить возможность злоупотребления правом субъектами финансовых обязательств в отдельных случаях в актах финансового законодательства необходимо конкретизировать критерии применения частноправовых конструкций, выступающих в качестве способов регулирования финансовых отношений. Например, совершенствование правового регулирования расходных финансовых обязательств, исполнение которых обеспечивается процедурой государственной закупки, должно идти по пути конкретизации условий и оснований расторжения государственного контракта по соглашению сторон. А применение таких частноправовых конструкций, как возмещение убытков, взыскание неустойки, начисление процентов не должно вступать в противоречие с публично-правовым механизмом возврата налогов, сборов, пеней или штрафов, необоснованно взысканных в бюджетную систему. В противном случае это может привести к неосновательному обогащению субъекта финансового обязательства, одновременно применившего нормы гражданского и финансового права в целях восстановления своего нарушенного экономического положения.

\footnotetext{
${ }^{26}$ Постановление АС Северо-Кавказского округа от 5 июня 2017 г. по делу № А53-22858/2016; Определение Верховного Суда РФ от 28 сентября 2017 № 308-ЭС17-13430 по делу № А53-22858/2016 // СПС «КонсультантПлюс».

${ }^{27}$ Постановление Пятнадцатого арбитражного апелляционного суда от 28 февраля 2017 № 15АП-823/2017 по делу N А53-22858/2016

${ }^{28}$ Концепция нового Кодекса Российской Федерации об административных правонарушениях [Электронный pecypc] // URL: http://static.government.ru по состоянию на 10.06.2019.
} 


\section{СПИСОК ЛИТЕРАТУРЫ}

1. Агапцов А. А., Шторгин С. И. Отчет о результатах экспертно-аналитического мероприятия «Мониторинг и оценка хода реализации приоритетной программы «Комплексное развитие моногородов». Утвержден коллегией Счетной палаты Российской Федерации 26 марта 2019 года // Бюллетень. 2019. № 7 (259). [Электронный ресурс] // URL: www.ach.gov.ru20.

21.

2. Агарков М. М. Общая часть советского обязательственного права. дисс д-ра юрид. наук. М.1938. С.

3. Васянина Е. Л. Обязательства в финансовом праве : монография / Е. Л. Васянина.- Москва : РУСАЙНС, 2020. С. 13.

4. Васянина Е. Л. О правовой природе бюджетного финансирования // Финансовое право. 2021. № 5. C. 3-6.

5. Волкова Н. Н. Рецепция гражданско-правовых норм в налоговом законодательстве : автореф. дис. .... канд. юрид. наук. - М., 2008. - 24 с.

6. Годэмэ Е. Общая теория обязательств / Е. Годэмэ - М.: Книга по Требованию,2020. С. 459.

7. Гражданское право. Учебник. Часть І. Издание третье, переработанное и дополненное. / под ред. А. П. Сергеева, Ю. К. Толстого. - М.: ПРОСПЕКТ, 1998. С. 484.

8. Запольский С. В., Васянина Е. Л.Субсидии и гранты - правовые инструменты развития экономики» // Хозяйство и право №11 2020.С.88-100.

9. Мамутов В. К. Хозяйственное право. Избранные труды. Екатеринбург: Бизнес, менеджмент и право, 2008. -302 с.

10. Моддерман В. Рецепция римского права. С- Петербругъ. Типо-Литографія А. Е. Ландау. Площадь Большого Театра, 2. 1888. С. 86.

11. Первоначальный проектъ общихъ положеній объ обязательствахъ. Санкт-Петербург. Типографія Правительствующаго Сената. 1890. С. 2.

12. Ровинский Е. А. Основные вопросы теории советского финансового права : монография / Е. А. Ровинский.- 2-е изд.. стер. -М.: Норма : ИНФРА-М, 2018. С. 20. 2001. C. 62 .

13. Фогельсон Ю. Б. Избраннее вопросы общей теории обязательств: Курс лекций.- Москва : Юрист,

\section{Васянина Елена Леонидовна}

ведущий научный сотрудник сектора административного

права и административного процесса

Института государства и права Российской академии наук

доктор юридических наук

Россия, 119019, г. Москва, ул. Знаменка, 10

E-mail: elenavasianina@yandex.ru

\section{E.L. VASYANINA}

\section{FINANCIAL OBLIGATIONS: DEFINITION AND LEGAL LIABILITY FOR INFRINGEMENT}

The article examines the problems of law-making implementation of the theoretical structure of financial obligations. The author pays special attention to the study of legal liability measures applied for violation of financial obligations, as well as to the issues of the reception of civil law norms in financial legislation.

В иелях упорядочения системы мер имущественной ответственности за нарушение финансовых обязательств автор приходит к выводу о челесообразности уменьшения количества штрафов за финансовые правонарушения и расширения круга оснований для применения в финансовом праве таких универсальные правовые структуры, такие как возмещение вреда, взыскание неустойки, начисление процентов и другие.

Keywords: financial obligation, income, expenses, tax, reception, liability, compensation for damage, collection of a penalty. 


\section{BIBLIOGRAPHY}

1. Agapcov A. A., Shtorgin S. I. Otchet o rezul'tatah ekspertno-analiticheskogo meropriyatiya «Monitoring i ocenka hoda realizacii prioritetnoj programmy «Kompleksnoe razvitie monogorodov». Utverzhden kollegiej Schetnoj palaty Rossijskoj Federacii 26 marta 2019 goda // Byulleten'. 2019. № 7 (259). [Elektronnyj resurs] // URL: www.ach.gov.ru20.

21.

2. Agarkov M. M. Obshchaya chast' sovetskogo obyazatel'stvennogo prava. diss d-ra yurid. nauk. M.1938. S.

3. Vasyanina E. L. Obyazatel'stva $v$ finansovom prave : monografiya / E. L. Vasyanina.- Moskva : RUSAJNS, 2020. S. 13.

6.

4. Vasyanina E. L. O pravovoj prirode byudzhetnogo finansirovaniya // Finansovoe pravo. 2021. № 5. S. 3 -

5. Volkova N. N. Recepciya grazhdansko-pravovyh norm v nalogovom zakonodatel'stve : avtoref. dis. .... kand. yurid. nauk. - M., 2008. - 24 s.

6. Godeme E. Obshchaya teoriya obyazatel'stv / E. Godeme - M.: Kniga po Trebovaniyu,2020. S. 459.

7. Grazhdanskoe pravo. Uchebnik. CHast' I. Izdanie tret'e, pererabotannoe i dopolnennoe. / pod red. A. P. Sergeeva, Yu. K. Tolstogo. - M.: PROSPEKT, 1998. S. 484.

8. Zapol'skij S. V., Vasyanina E. L.Subsidii i granty - pravovye instrumenty razvitiya ekonomiki» // Hozyajstvo i pravo №11 2020.S.88-100.

9. Mamutov V. K. Hozyajstvennoe pravo. Izbrannye trudy. Ekaterinburg: Biznes, menedzhment i pravo, 2008. $-302 \mathrm{~s}$.

10. Modderman V. Recepciya rimskogo prava. S- Peterbrug". Tipo-Litografiya A. E. Landau. Ploshchad' Bol'shogo Teatra, 2. 1888. S. 86.

11. Pervonachal'nyj proekt" obshchih" polozhenij ob" obyazatel'stvah". Sankt-Peterburg. Tipografiya Pravitel'stvuyushchago Senata. 1890. S. 2.

12. Rovinskij E. A. Osnovnye voprosy teorii sovetskogo finansovogo prava : monografiya / E. A. Rovinskij.2-e izd.. ster. -M.: Norma : INFRA-M, 2018. S. 20.

62.

13. Fogel'son Yu. B. Izbrannee voprosy obshchej teorii obyazatel'stv: Kurs lekcij.- Moskva : YUrist, 2001. S.

\section{Vasyanina Elena Leonidovna}

Leading Researcher, Administrative Sector

law and administrative process

Institute of State and Law of the Russian Academy of Sciences

Doctor of Law

Russia, 119019, Moscow, st. Znamenka, 10

E-mail: elenavasianina@yandex.ru 